\title{
«ESTUDIANTES, USTEDES SON LA GLORIA Y LA JOYA MÁS HERMOSA DE UNA UNIVERSIDAD CATÓLICA"
}

DISCURSO DEL MONS. DR. JOAQUÍN MARTINEZ VALLS

RECTOR DE LA UNIVERSIDAD CATÓLICA SEDES SAPIENTIAE EN OCASIÓN DE

LA RESOLUCIÓN DE AUTONOMÍA UNIVERSITARIA POR PARTE DEL CONSEJO

Nacional para la Autorización de Funcionamiento de Universidades

(CONAFU)

Excmo. Sr. Gran Canciller, Emmo. Sr. Cardenal, Sr. Presidente y miembros del CONAFU. Sr. Embajador de Italia, Consejero Cultural de España. Dignisimas autoridades universitarias, religiosas, civiles y militares. Competente personal docente, distinguidos alumnos, personal de servicios y administración. Señoras y señores, amigos todos.

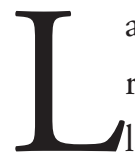

a constitución del Perú, en su artículo 50, dice: «Dentro de un régimen de independencia y autonomía, el Estado reconoce a la Iglesia Católica como elemento importante en la formación histórica, cultural y moral del Perú, y le presta su colaboración. El Estado respeta otras confesiones y puede establecer formas de colaboración con ellas».

Lo que acabo de leer no solo es la constatación de un hecho gozoso y rigurosamente histórico. Es también la confirmación de una auténtica realidad «aún» presente y esperamos que en el futuro también lo sea. El evento que estamos celebrando es buena prueba de ello.

Llegados a este punto, lo primero que brota en mí, a fuera de bien nacido, es un enorme agradecimiento a tantas y tantas circunstancias, instituciones $y$, sobre todo, personas: en primer lugar, a la vida, que me ha dado tanto; a mis padres, que hicieron posible que yo esté ahora acá. 
Y sabemos que el autor de la vida, de toda vida, es Dios nuestro Padre. Él la da y, según mi opinión, que creo coincide con la de la Iglesia, única y exclusivamente Él puede disponer de ella. Gracias por tanto al Señor, autor de todo bien y que sigue haciendo maravillas en su pueblo, en nuestro pueblo. Y entre estas maravillas, hemos de contar nuestra Universidad, que comenzó hace poco más de cinco años como un grano de mostaza y se está convirtiendo, como la parábola del evangelio, en un frondoso árbol, que, con el esfuerzo de todos, ha de crecer todavía más. Gracias, Mons. Gran Canciller, por su confianza y por esta investidura. Gracias a mi Rector de la Universidad de Alicante, a la que sigo perteneciendo como profesor principal, y que no ha podido venir, y a mi Obispo de Alicante, acá presente, por autorizarme, en su día, a aceptar la amable invitación de Mons. Lino. Personalmente afirmo que nadie ha podido obtener tanto a cambio de tan poco. Mi deuda a tantas queridas personas es inmensa y es de justicia reconocerlo ante nuestra comunidad universitaria. Sé que cuento con el insustituible apoyo y estímulo de todos ustedes. Tengo el mejor recuerdo que puedo de vuestro compañerismo e incondicional amistad: de los doctores Roger Rodríguez Iturri, Ing. Aliaga, Clara Caselli, Biagio D’Angelo, y antes Gian Corrado Peluso; de Gian Battista Bolis, Padre Pedro Martínez, entre otros. Y esto es lo que me alienta, a pesar de mis años y limitaciones, a seguir adelante, mientras el Señor conserve mi vida, mis fuerzas y, sobre todo, mi cabeza.

He dicho con el esfuerzo de todos. Efectivamente la Universidad es obra de todos, es una "Fuenteovejuna», todos a una. En primer lugar, damos gracias por la feliz inspiración otorgada a Mons. Lino, que plantó la semilla en un medio necesitado de cultura y de promoción de sus gentes, sin que para ellos supusiera excesivos costos, dada la situación social del 
Cono Norte; a las instituciones de países especialmente de España e Italia, y particulares que han apoyado generosamente en las necesidades de toda índole de este Centro; a las Autoridades y personal docente, que con su entrega y dedicación han hecho posible que esta Universidad haya conseguido un merecido prestigio en el mundo universitario.

Y llegados a este punto he de dejar bien claro que esta Universidad es universal, es de la Iglesia; como tal, es de todos. Sin embargo, es de justicia reconocer y agradecer los enormes servicios y entrega del movimiento Comunión y Liberación, que tanto ha hecho, está haciendo y esperamos que siga haciendo por esta Casa. Pero, insisto, todos están invitados a participar sin exclusivismos, y somos muchos los que trabajamos en la Universidad, que pertenecen a otros movimientos o no pertenecemos a ninguno, con la única condición de respetar y proclamar los ideales cristianos, y el amor de servicio a nuestro pueblo.

Mi agradecimiento a todo el personal de administración y servicios por sus desvelos y cuidado de los detalles, necesarios para un buen funcionamiento de la Institución.

Gracias también a los miembros del CONAFU, que con sus exigencias han posibilitado un esfuerzo cada vez mayor por nuestra parte que vamos a continuar. Saben que siempre les hemos recibido en esta Casa con cordialidad, respeto y reconocimiento de la alta labor que están realizando.

A todos los que han podido estar aquí, algunos viniendo de lejos, y/o abandonando sus tareas, y acompanándonos en este sencillo acto, nuestro agradecimiento más profundo. También les quisiéramos transmitir la necesidad de contar siempre con vuestra visión crítica y vuestro apoyo personal e institucional, solicitud que hacemos extensible a toda la Comunidad Universitaria. 
Finalmente, como dicen los ingleses, the last but not the least, los alumnos. Ustedes son la gloria y la joya más hermosa de este Centro. Ustedes son los protagonistas principales. Contamos en la actualidad con casi 3500 alumnos y ya se han graduado un total de 289, entre las carreras de Ciencias Económicas Comerciales y Ciencias de la Educación. Contamos con casi 200 profesores. Y vamos a seguir avanzando. He dicho y repito que Vds. son los protagonistas, porque todos, desde el Rector, pasando por las autoridades y los docentes estamos para vuestro servicio, para forjar auténticos hombres y mujeres bien preparados y con sentido de responsabilidad y de cumplimiento del deber, para procurar en cada uno de Vds. una formación integral, que les capacite para asumir puestos de responsabilidad en este Perú tan querido. En definitiva, en esta Universidad hemos querido que con Vds. nuestro lema fueran las palabras de Jesús: "No he venido a ser servido, sino a servir» (Mt 20, 28). Hemos querido servirles. Y deseamos que este sea también el lema de todos en el futuro, servir al pueblo, y no servirse del pueblo, como quizá algunos hayan hecho en el pasado.

Y para que esto no quede en solo parole parole, hemos de recordar:

Punto 1. Somos una Universidad Católica, por tanto, asumimos plena e incondicionalmente lo establecido por la Constitución Apostólica Ex Corde Ecclesia sobre las Universidades Católicas, del 15 de agosto de 1990.

Artículo 2. 2. Una Universidad Católica, en cuanto católica, inspira y realiza su investigación, la enseñanza y todas las demás actividades según los ideales, principios y actitudes católicos.

Artículo 5. (La Universidad Católica en la Iglesia) 1. Toda Universidad Católica debe mantener la comunión con la Iglesia universal y con la Santa Sede; debe estar en estrecha comunión con la Iglesia particular y, en especial, 
con los Obispos diocesanos de la región o de la nación en la que está situada.

Por esto ponemos toda nuestra confianza en la ayuda y protección del Señor, en la intercesión de la «Sedes Sapientiae» y en nuestro esfuerzo personal. Nuestra confianza en Dios, como si todo dependiera exclusivamente de Él. Nuestro esfuerzo, entrega y empeño totales, como si todo dependiera de nosotros.

Punto 2. Hemos de consolidar el espacio de expansión futura de nuestra Universidad en las proximidades del Campus actual y en la ciudad; planificar nuestra oferta docente futura con criterios rigurosos universitarios y enseñanza del más alto nivel. Nuestro sustantivo es Universidad, por tanto, nos preocuparemos de formar en valores, pues la ciencia sin conciencia es la ruina del hombre.

Punto 3. Hemos de esforzarnos en mejorar los servicios que prestamos a la Comunidad Universitaria, en especial aquellos que afectan a la formación integral de la persona, y a los derechos humanos, con especial referencia a los que inciden en la sensibilidad social. Nuestros profesores y todo el personal han de estar inmersos en una formación continua, preparar bien sus clases e impartirlas con solvencia, elegancia y con puntualidad.

Punto 4. Adecuaremos nuestra Universidad a los grandes retos del espacio común europeo y mundial de la enseñanza superior para el año 2010. Hemos de estar al día en todo. Y para ello, como sostuve en una intervención el pasado 5 de julio en Roma: 


\section{JOAQUÍN MARTÍNEZ VALLS}

La irreversible globalización en la que todos estamos inmersos, nos obliga a plantearnos algo de suma importancia. La cuestión que debiera plantearse cualquier persona que no coloque como objetivo primario el provecho económico respecto a las diversas culturas e idiosincrasias de los diferentes pueblos, con los que necesariamente hemos de tratar, es no cómo las asimilamos, que equivale a una aniquilación o anulación, sino cómo se las integra. Con la asimilación se pierde o se puede perder casi todo lo que se tiene, pero con la integración se mantiene. Hay que evitar una uniformización cultural, respetando las culturas propias y las idiosincrasias de los pueblos. $Y$ este es otro de los grandes riesgos. Y todo ello por el gran respeto que merecen como personas. Como una servidumbre al gran don de la libertad. Por tanto, proponiendo, pero no imponiendo. $Y$ manteniendo siempre un gran respeto a la libertad de las gentes, a nivel particular y a nivel colectivo, ya sea como sujetos pertenecientes a una cultura singular o como miembros pertenecientes a pueblos indigenas con culturas particulares. $Y$ formar en los valores clásicos conocidos, pero de modo que todos sean conscientes de la igualdad de derechos y de oportunidades, sin que quepan distinciones o privilegios por razones de raza, sexo, lengua, religión, nacionalidad, etc. En suma, se reciben los beneficios del progreso y de los avances cientificos, pero se mantienen los propios valores, costumbres y tradiciones. Que todos se sientan ciudadanos del mundo y de verdad se sientan hijos del mismo Dios. (Acá recordar a Tácito sobre los britanos que imitaron togas, costumbres, etc. de los romanos. "Todo lo cual llamaban los no instruidos cultura, siendo parte de la esclavitud»)

Pienso que hemos de asumir sin restricciones las conclusiones del congreso de abril pasado en Porto Alegre. Nos hemos de comprometer en humanizar la globalización. Hemos de asumir 
la responsabilidad de la formación integral del hombre; especialmente con los valores tradicionales cristianos; y en la conservación y defensa de los valores e idiosincrasia típicos de nuestro pueblo, con sentido de responsabilidad e inculcarles que sepan y quieran comprometerse en la vida pública de este entrañable pueblo del Perú, pero con honradez, con justicia y con verdad. Para servir al pueblo y no para servirse del pueblo.

Para que esto sea posible, permitaseme recordar las sabias de Benedicto XVI el pasado día lunes 11 de septiembre en Ratisbona, durante su visita a Alemania. En el aula magna de aquella famosa Universidad, de manera retórica preguntó a los presentes si aún hoy es posible creer, si es algo racional. La respuesta la dio el propio Papa al recordar los intentos "de al menos una parte de la ciencia" en dar "una explicación del mundo en la que Dios sea superfluo». "Pero cada vez que parecen conseguirlo, de nuevo parece evidente que "Las cuentas del hombre, sin Dios, no salen», sentenció. El Papa Benedicto XVI aseguró que solo «si la razón y la fe avanzan juntas de un modo nuevo", el hombre podrá superar los peligros que emergen de las «nuevas posibilidades abiertas a la humanidad»

Termino. Sé que vamos a recibir beneplácitos y felicitaciones. Las agradeceremos cordialmente. Pero también agradeceremos las críticas constructivas, vengan de donde vengan. Soy consciente de que tampoco nos van a faltar reproches y críticas, a veces duras e injustas. Pero en este caso nos acordaremos de las palabras de don Quijote: "Ladran Sancho, luego cabalgamos». 
En fin, señoras y señores, y amigos todos. Hemos pasado el Rubicón. Y decimos, como Julio Cesar, alea iacta est. Y como hombres de fe, permítanme que termine con una hermosa oración, recordando al poverello de Asís: Y que si todos lo realizamos, podría ser el secreto para sońar en cielos nuevos y tierra nueva para este entrañable pueblo del Perú.

\section{ORACIÓN DE LA PAZ}

Señor, haced de mi un instrumento de paz:

que alli donde haya odio, ponga yo amor, donde haya ofensa, ponga yo perdón, donde haya discordia, ponga unión, donde haya error, ponga verdad, donde haya duda, ponga fe, donde haya desesperación, ponga esperanza, donde haya tinieblas, ponga vuestra luz donde haya tristeza, ponga yo alegría.

Oh Maestro, que no me empeñe tanto en ser consolado, como en consolar;

en ser comprendido como en comprender; en ser amado, como en amar.

Porque dando, se recibe, olvidando, se encuentra; perdonando, se es perdonado; muriendo, se resucita a la vida eterna. 


\section{.0 \\ A \\ r. W kw iw \\ $\left.G^{R}:{ }^{\circ}\right)$ or A) $=10$ ora Hall \\ तil? \\ the

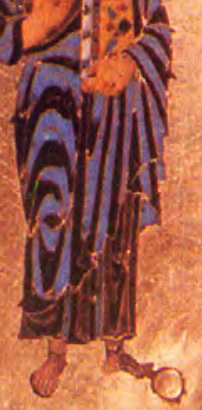

.

\section{(1)}

$\therefore$ 극 $\frac{\pi}{i}$

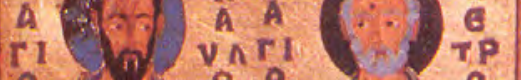

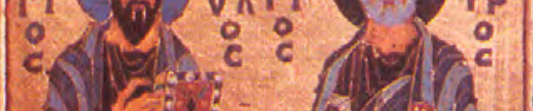

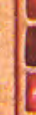

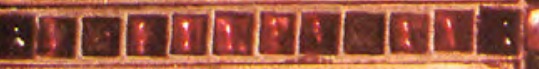

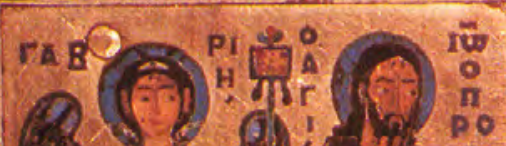

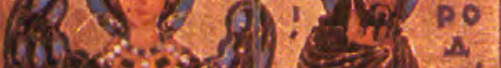

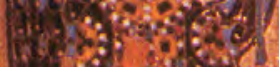

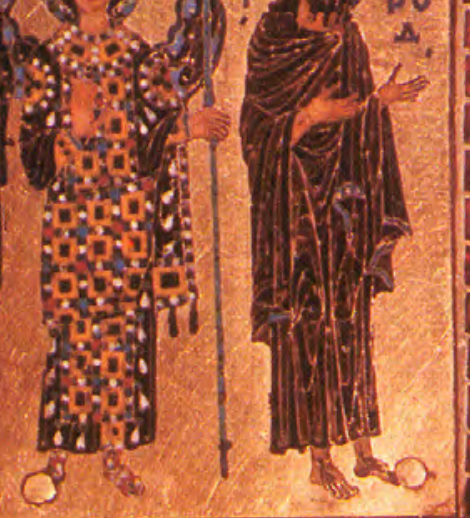

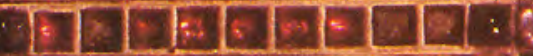

A

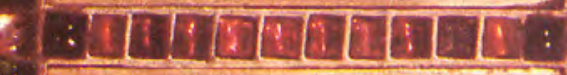

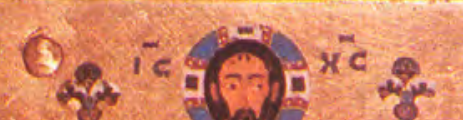

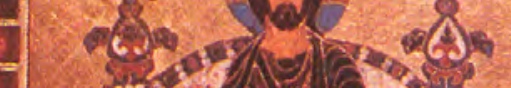

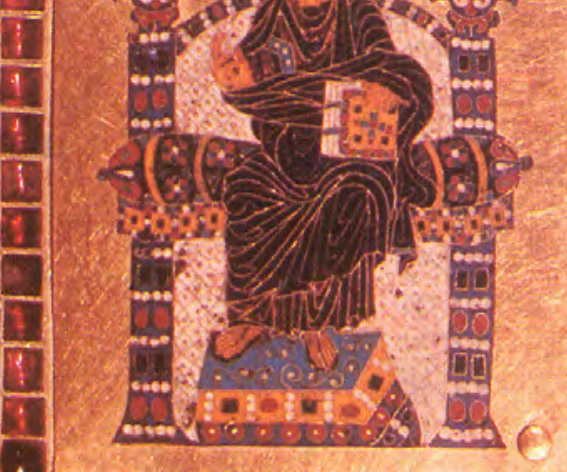

\section{$-$ \\ -}
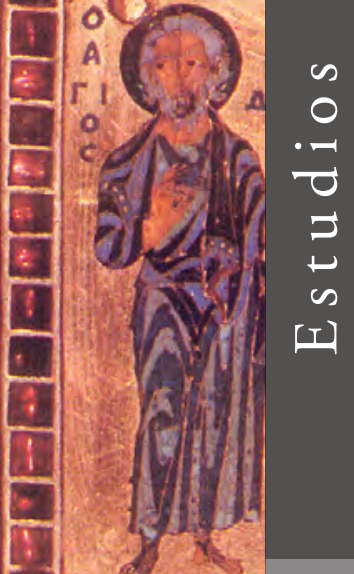